\title{
Retrosigmoid Approach for Resection of Medium-Sized Vestibular Schwannoma
}

\author{
Michael J. Link ${ }^{1,2}$ Colin L. W. Driscoll ${ }^{1,2}$ Yening Feng ${ }^{2}$ Maria Peris-Celda ${ }^{1}$ Christopher S. Graffeo ${ }^{1}$ \\ ${ }^{1}$ Department of Neurologic Surgery, Mayo Clinic, Rochester, \\ Minnesota, United States \\ 2 Department of Otorhinolaryngology, Mayo Clinic, Rochester, \\ Minnesota, United States

\begin{abstract}
Address for correspondence Michael J. Link, MD, Department of Neurosurgery, Department of Otolaryngology-Head and Neck Surgery, Mayo Clinic School of Medicine, Rochester, MN 55905,
\end{abstract} \\ United States (e-mail: link.michael@mayo.edu).
}

J Neurol Surg B 2019;80(suppl S3):S284.

\begin{abstract}
Keywords

- retrosigmoid

- vestibular schwannoma

- acoustic neuroma

- skull base

Objectives This video was aimed to describe the relevant anatomy and key surgical steps of retrosigmoid approach for gross total resection of a medium-sized vestibular schwannoma (VS).

Design The procedure is described in a surgical instructional video.

Setting The surgery took place at a tertiary skull base referral center.

Participant Patient is a 63-year-old woman who reported with nonserviceable hearing (Pure Tone Average $60 \mathrm{~dB}$ Hearing level, Word Recognition Score 45\%), occasional tinnitus, and a VS in the left cerebellopontine angle (CPA), extending into internal auditory canal (IAC), measuring $1.7 \mathrm{~cm}$ parallel to the petrous temporal bone. Main Outcome Measures The VS was resected by retrosigmoid approach.

Results The surgery results gross total resection of the VS with postoperative HouseBrackmann grade 1 facial nerve function and no postoperative complications.

Conclusion The retrosigmoid approach is a good strategy to remove VS involving the CPA and the IAC.

The link to the video can be found at: https://youtu.be/B6K_UkrKitg.
\end{abstract}

Conflict of Interest

None.

\section{回倏回}

www.thieme.com/skullbasevideos

www.thieme.com/jnlsbvideos

received

May 31, 2018

accepted after revision

November 11, 2018

published online

March 4, 2019
DOI https://doi.org/

10.1055/s-0039-1677848.

ISSN 2193-6331. (c) 2019 Georg Thieme Verlag KG
Stuttgart · New York

License terms

(c) $\odot \ominus$ 